\title{
The temporal characteristics of functional activation in Broca's area during overt picture naming
}

Citation for published version (APA):

Schuhmann, T., Schiller, N. O., Goebel, R., \& Sack, A. T. (2009). The temporal characteristics of functional activation in Broca's area during overt picture naming. Cortex, 45(9), 1111-1116. https://doi.org/10.1016/j.cortex.2008.10.013

Document status and date:

Published: 01/01/2009

DOI:

10.1016/j.cortex.2008.10.013

Document Version:

Publisher's PDF, also known as Version of record

Document license:

Taverne

Please check the document version of this publication:

- A submitted manuscript is the version of the article upon submission and before peer-review. There can be important differences between the submitted version and the official published version of record.

People interested in the research are advised to contact the author for the final version of the publication, or visit the DOI to the publisher's website.

- The final author version and the galley proof are versions of the publication after peer review.

- The final published version features the final layout of the paper including the volume, issue and page numbers.

Link to publication

\footnotetext{
General rights rights.

- You may freely distribute the URL identifying the publication in the public portal. please follow below link for the End User Agreement:

www.umlib.nl/taverne-license

Take down policy

If you believe that this document breaches copyright please contact us at:

repository@maastrichtuniversity.nl

providing details and we will investigate your claim.
}

Copyright and moral rights for the publications made accessible in the public portal are retained by the authors and/or other copyright owners and it is a condition of accessing publications that users recognise and abide by the legal requirements associated with these

- Users may download and print one copy of any publication from the public portal for the purpose of private study or research.

- You may not further distribute the material or use it for any profit-making activity or commercial gain

If the publication is distributed under the terms of Article $25 \mathrm{fa}$ of the Dutch Copyright Act, indicated by the "Taverne" license above, 


\title{
Special issue: Research report
}

\section{The temporal characteristics of functional activation in Broca's area during overt picture naming}

\author{
Teresa Schuhmann ${ }^{a, *}$, Niels O. Schiller ${ }^{a, b}$, Rainer Goebel ${ }^{a}$ and Alexander T. Sack ${ }^{a}$ \\ ${ }^{a}$ Department of Cognitive Neuroscience, Faculty of Psychology and Neuroscience, Maastricht University, Maastricht, The Netherlands \\ ${ }^{\mathrm{b}}$ Leiden Institute for Brain and Cognition (LIBC), Leiden, The Netherlands
}

\section{A R T I C L E I N F O}

Article history:

Received 16 June 2008

Reviewed 27 August 2008

Revised 28 September 2008

Accepted 22 October 2008

Published online 6 December 2008

Keywords:

Transcranial magnetic stimulation

Picture naming

Broca's area

Language production

Speech production

\begin{abstract}
A B S T R A C T
The opercular and triangular sections of the inferior frontal gyrus, also known as Broca's area, have been shown to be involved in various language tasks. In the current study we investigated both the functional role, as well as the precise temporal involvement of Broca's area during picture naming. We applied online event-related transcranial magnetic stimulation (TMS) to Broca's area at five different time points after picture presentation, aiming to cover the complete language production process. Applying real TMS at $300 \mathrm{msec}$ after picture presentation led to an increase in picture naming latency, whereas sham stimulation and real stimulation at earlier and later time windows did not result in any changes in reaction time (RT). Our methodological approach enabled us to get insight into the temporal characteristics of the involvement of this brain area during picture naming. Making use of this information and directly relating it to psycholinguistic models, we conclude that Broca's area may be involved in the process of syllabification during overt speech production.
\end{abstract}

(c) 2008 Elsevier Srl. All rights reserved.

\section{Introduction}

Our ability to communicate and comprehend verbal language represents one of the most crucial and complex human cognitive skills. By employing single case lesion studies, Broca (1861) and Wernicke (1874) were pioneers in the attempt to directly relate different aspects of language processing to the proper functioning of distinct regions of the cerebral cortex. With the advent of modern functional brain imaging techniques, a systematic non-invasive investigation of the neural correlates of language also became available in healthy volunteers. Until today, a vast amount of studies have continued to reveal detailed insights into the exact functional neuroanatomy underlying speech production using electrophysiological [magnetoencephalography (MEG) (Salmelin, 2007) and electroencephalography (EEG) (Schiller et al., 2003; Schmitt et al., 2000)] and metabolic brain imaging techniques (see for example Gernsbacher and Kaschak, 2003; Binder et al., 1997). Other studies have utilised transcranial magnetic stimulation (TMS) to transiently disrupt neural processing, thereby effectuating a quantifiable change in behavioural performance when it is applied to an area functionally involved in the task at question (Pascual-Leone et al., 2000). These studies have contributed to the understanding of the functional relevance of language-related brain areas to the behavioural execution of various language tasks (Andoh et al.,

\footnotetext{
* Corresponding author. Department of Cognitive Neuroscience, Faculty of Psychology and Neuroscience, Maastricht University, P.O. Box 616, 6200 MD Maastricht, The Netherlands.

E-mail address: t.schuhmann@psychology.unimaas.nl (T. Schuhmann). 0010-9452/\$ - see front matter ( 2008 Elsevier Srl. All rights reserved.
} doi:10.1016/j.cortex.2008.10.013 
2006; Devlin et al., 2003; Mottaghy et al., 1999, 2006; Naeser et al., 2005; Nixon et al., 2004; Sakai et al., 2002; Shapiro et al., 2001). However, only few of these TMS studies employed the advantage of event-related TMS to track the exact time point of functionally relevant neural activity during language production. Moreover, some neglected the high inter-individual variance in the anatomy of participants' brains. They applied TMS to sites that were defined by anatomical landmarks of the skull or standardised group coordinates, instead of making use of individual anatomical brain mapping.

Here we investigated both the functional role as well as the precise temporal involvement of Broca's area during language production, as taking place during picture naming. Broca's area is an anatomically complex region which includes the pars opercularis (F3Op), the pars triangularis (F3Tr), and the pars orbitalis, all of which show anatomical variability between participants. We used individual anatomical mapping and frameless stereotaxy to precisely map and target Broca's area in each individual participant. We applied online event-related triple-pulse TMS (tpTMS), while participants were performing a picture naming task, at various time points after picture presentation. This enabled us to not only receive information about whether Broca's area is functionally relevant during picture naming, but to also identify exactly at which precise point in time the neural activity in Broca's area contributes to the processes of picture naming (Sack and Linden, 2003; Walsh and Pascual-Leone, 2003). Event-related tpTMS has previously been shown to be more suited for inducing measurable behavioural effect sizes in higher cognitive functions than single-pulse TMS, while still providing sufficient temporal resolution (Sack et al., 2005). To control for effects caused by factors other than the direct magnetic stimulation of the brain, we included sham stimulation.

\section{Methods}

\subsection{Participants}

Twelve healthy volunteers ( 5 men; mean age 23.2 years, standard deviation 2.08, range 20-26) participated in the study. All participants were native Dutch speakers, had normal or corrected-to-normal vision and had no history of neurological or psychiatric disorders. They received medical approval for participation and gave their written informed consent after being introduced to the procedure. The study was approved by the local Medical Ethical Commission.

\subsection{Overall study design}

We combined the methods of structural magnetic resonance imaging (MRI) and neuronavigated TMS to study the influence of a controlled neural activity disruption of Broca's area on picture naming latencies. Participants were tested in three separate sessions. In the first session, we obtained anatomical measurements of all participants using MRI. In the second and third session, participants were either stimulated with triplepulse real TMS or with triple-pulse sham TMS, respectively, while performing a behaviourally controlled picture naming task. This study design and methodological approach enabled us to first define the target brain area based on the individual anatomical data and to subsequently neuronavigate the TMS coil to the anatomically defined stimulation site in each participant. The MRI-guided TMS neuronavigation was monitored online throughout the experiment, allowing for a precise determination of the actual stimulation site during task execution.

\subsection{Stimuli, paradigm and procedure}

A set of ten simple white-on-black line drawings was used as target pictures. All items corresponded to monomorphemic, monosyllabic Dutch nouns. They were taken from the picture database of the Max Planck Institute for Psycholinguistics in Nijmegen, The Netherlands. All picture names had a length between three and five segments (phonemes). Each picture had a mean frequency of occurrence between 10 and 73 per million as determined by CELEX (Baayen et al., 1995), i.e., all pictures were of moderate frequency and had a name agreement of 100 percent. The drawings were presented on a computer screen in front of the participant. The stimuli subtended a visual angle of $2.82^{\circ} \times 4.57^{\circ}$ and were displayed in the centre of the monitor. Each trial consisted of a fixation cross presented between 5900 and 7900 msec, followed by a black screen for $100 \mathrm{msec}$. Thereafter, one of the pictures was presented for $750 \mathrm{msec}$. Participants were instructed to name the presented picture as quickly as possible by responding into a microphone. After a jittered delay between 6 and $8 \mathrm{sec}$, a new trial began (see Fig. 1).

\subsection{Response time analysis}

The entire experiment was recorded with a microphone positioned on the table in front of the participant. Acoustic information was digitised with the digital audio editing software GoldWave v 5.17 (GoldWave, Newfoundland, Canada) with a sampling rate of $44 \mathrm{kHz}$. Prior to determining the speech onset, the acoustic signal was filtered to reduce noise. The latency of the verbal responses (reaction time - RT) was measured on the screen using speech wave envelopes (see Fig. 2).

\subsection{MRI measurements}

A high-resolution anatomical image was obtained from each participant in a 3-T magnetic resonance scanner (Siemens Allegra MR Tomograph; Siemens AG, Erlangen, Germany) at the Faculty of Psychology and Neuroscience, Maastricht University, The Netherlands. The T1-weighted data set was acquired with the help of a magnetisation-prepared rapid acquisition gradient echo (MPRAGE) sequence or a T1weighted structural scan with an isotropic resolution of $1 \mathrm{~mm}$ using a modified driven equilibrium Fourier transform (MDEFT) sequence with optimised contrast for grey matter and white matter and imaging parameters.

\subsubsection{Cortical-surface reconstruction}

Data were analysed using the BrainVoyager QX 1.8 software package (BrainInnovation, Maastricht, The Netherlands). The high-resolution anatomical recordings were used for surface 


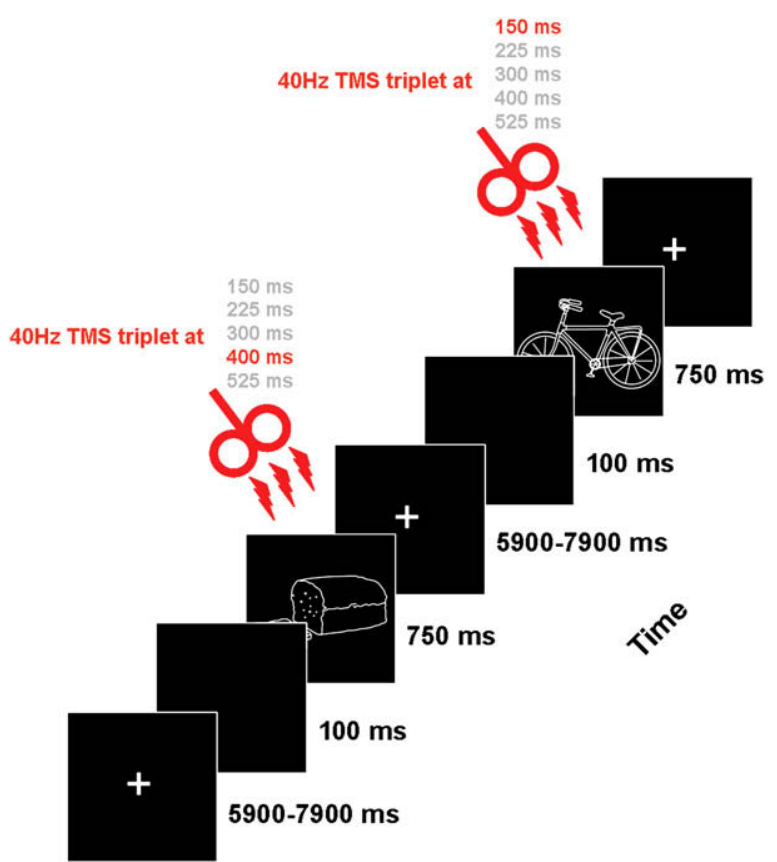

Fig. 1 - Experimental Paradigm. A trial consisted of the presentation of the fixation cross followed by a black screen, followed by the presentation of the picture. After picture presentation, tpTMS was applied randomly at one out of 5 different time windows. In the first trial shown in the figure, the TMS pulses were applied $400 \mathrm{msec}$ after picture presentation and in the second trial shown, at 150 msec after picture presentation. Participants were instructed to name the presented picture as quickly as possible by responding into a microphone. After a jittered delay between 6-8 sec, a new trial began.

reconstruction of the left hemisphere of each participant. The surface reconstruction was performed in order to recover the exact spatial structure of the cortical sheet and to improve the visualisation of the anatomical gyrification.

\subsubsection{Co-registration of stereotaxic and MRI data}

For a precise positioning of the stimulation coil, we made use of the BrainVoyager TMS Neuronavigator (BrainInnovation, Maastricht, The Netherlands). This frameless stereotaxic system allows for an online individual navigation of a TMS coil above a specific anatomical area of the brain, as well as an imaging-guided navigation of the TMS coil to functionally defined brain regions-of-interest (see Sack et al., 2006).

\subsection{TMS measurements}

\subsubsection{TMS apparatus and stimulation parameters} Biphasic TMS pulses were applied using the MagProX100 stimulator (Medtronic Functional Diagnostics A/S, Sklovunde, Denmark) and a figure-of-eight coil (MC-B70, inner radius $10 \mathrm{~mm}$, outer radius $50 \mathrm{~mm}$ ). The maximum output of this coil and stimulator combination is approximately 1.9 Tesla and $150 \mathrm{~A} / \mu \mathrm{S}$. A specific figure-of-eight placebo coil (MC-P-B70) was also employed in order to reproduce the same acoustic stimulation as the active coil while not inducing the magnetic field (sham stimulation). The coils were manually held tangentially to the skull with the coil handle oriented perpendicular to the opercular part of the inferior frontal gyrus using the online visualisation function of the BrainVoyager TMS Neuronavigator. Event-related tpTMS was applied with an interpulse-interval of $25 \mathrm{msec}(40 \mathrm{~Hz})$ at 120\% motor threshold (MT).

\subsubsection{TMS localisation}

Broca's area is typically defined in terms of areas F3Op and F3Tr of the inferior frontal gyrus, represented in Brodmann's (Brodmann, 1909) cytoarchitectonic map as areas 44 and 45. We targeted area F3Op of the inferior frontal gyrus (thus the posterior part of Broca's area) for stimulation. The stimulation site was localised using frameless stereotaxy (TMS neuronavigation; Sack et al., 2006; Cohen Kadosh et al., 2007) for both real and sham stimulation. Using such a TMS neuronavigation system enabled us to account for inter-individual differences in anatomical brain structures while stimulating. The average stimulation site coordinates in Talairach space were: $x=-49.5 ; y=12.83 ; z=24.83$.

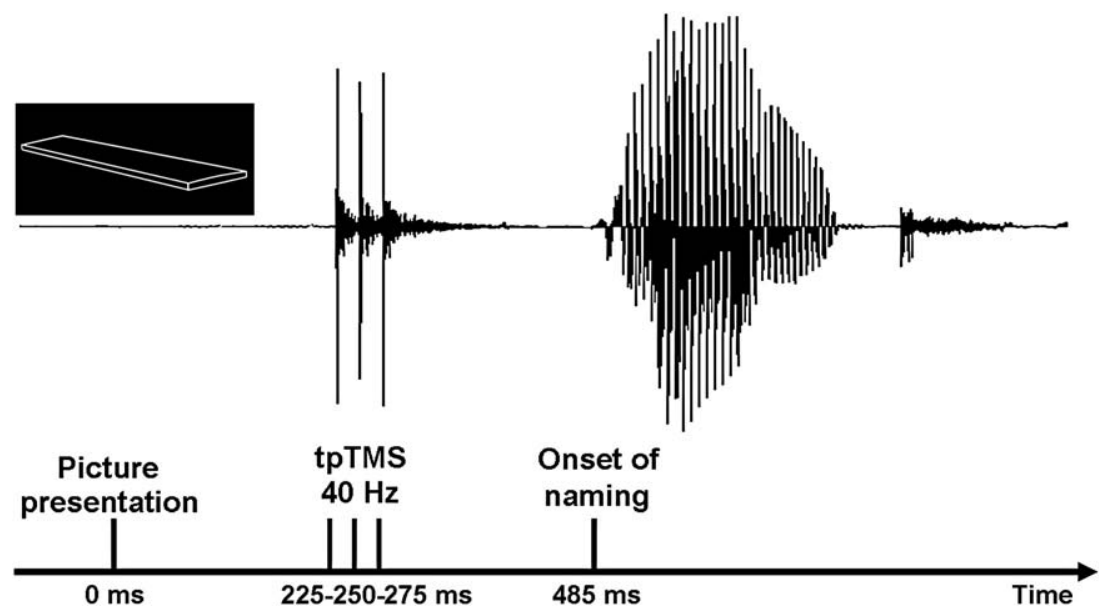

Fig. 2 - Trial-by-trial naming latency analysis. The latency of the verbal responses (RT) was measured on the screen using speech wave envelopes. Onset of naming was defined as the first detectable amplitude in the digitised speech-waves. 


\subsubsection{TMS procedure}

Individual MTs were determined as the intensity at which the stimulation of the left motor cortex with single-pulse TMS resulted in a visible movement of the contralateral thumb in $50 \%$ of the trials. The MTs of the participants ranged from $27 \%$ to $42 \%$ of maximum stimulator output (mean $=35.40 \%(51.6 \mathrm{~A}$ / $\mu \mathrm{S}), \mathrm{SD}=4.6)$. The mean stimulation intensity was set at $120 \%$ of the MT and therefore resulted in $42.5 \%(63.75 \mathrm{~A} / \mu \mathrm{S})$ of maximum stimulator output (range $33 \%-50 \%, \quad \mathrm{SD}=5.3$ ). Throughout the entire experiment, participants wore earplugs to protect their ears from the clicking sound and to minimise the interference of the sounds during the task.

Participants were tested with event-related tpTMS in two separate sessions. In one session, participants were stimulated with real TMS, in the other session with sham TMS. The sequence of stimulation type was counterbalanced across participants. Prior to starting with the experiment, participants were familiarised with the stimuli and practised naming the stimuli repeatedly to reach a stable performance level in naming latency. Each experimental session consisted of 60 trials, divided into 4 blocks of fifteen trials each. Stimuli were presented and pulses were triggered using the software package "Presentation" (http://nbs.neuro-bs.com).

Event-related tpTMS was applied at five different points in time following picture presentation onset, namely at 1) 150 175-200 msec, 2) 225-250-275 msec, 3) 300-325-350 msec, 4) 400-425-450 msec, and 5) 525-550-575 msec. In a sixth condition, no TMS pulses were applied during the trial. This latter condition served as an online baseline measurement. The presentation of the pictures and the TMS time window conditions were fully randomised across trials within each session.

\section{Results}

Two participants did not go through the entire experimental TMS session since they experienced discomfort due to strong contractions of face muscles and were therefore excluded from the analysis. Incorrect trials of the remaining ten participants were excluded from the naming latency analysis. Incorrect trials (errors) were defined as either semantically incorrect responses, hesitations or extremely delayed responses (responses taking longer than $2000 \mathrm{msec}$ ).

The effect of TMS on Broca's area was tested at the abovementioned five time intervals. The same set of intervals was also tested applying sham TMS. To correct for the positive skew of the response times distribution, a logarithmic transformation of the data was performed. Moreover, response times that were above or below 2 standard deviations of the mean were defined as outliers and excluded from the naming latency analysis. In the real TMS session, $4.17 \%(\mathrm{SD}=.14)$ of the data was defined as outliers, whereas $2.33 \%(\mathrm{SD}=.15)$ of the data in the sham TMS condition were outliers.

\subsection{TMS-induced changes in picture naming accuracy}

The mean error rates were calculated for each time window for both the sham and real stimulation. The mean amount of errors during the real TMS experiment ranged from .01 $(\mathrm{SD}=.03)$ up to $.05(\mathrm{SD}=.07)$ in the different time windows.
During the sham TMS experiment, the mean amount of errors was comparable, ranging from $.01(\mathrm{SD}=.04)$ to $.04(\mathrm{SD}=.07) . \mathrm{A}$ two-factorial ANOVA with stimulation type (real TMS us sham TMS) and time window (no stimulation, stimulation at 150, $225,300,400$, and $525 \mathrm{msec}$ after stimulus presentation) as the two within-subject factors did not reveal a significant effect of time window $[F(5,45)=.769, p=.577]$ nor stimulation type $[F(1,9)=1.569, p=.242]$. Moreover, there was no interaction between stimulation type and time window $[F(5,45)=1.058$, $p=.396]$, revealing that the error rate not only did not differ between time windows within one stimulation type, but that the time windows did also not differ between the two stimulation types.

\subsection{TMS-induced changes in picture naming latency}

The mean RTs were calculated for each time window for sham and real stimulation. As can be seen in Fig. 3, during the sham TMS condition, mean RTs did not vary considerably at any of the time points of stimulation. In fact, the RTs during sham stimulation for every time window (TMS at 150: $453 \mathrm{msec}$, $\mathrm{SD}=44.08$; TMS at 225: $453 \mathrm{msec}, \mathrm{SD}=32.91$; $\mathrm{TMS}$ at 300 : $461 \mathrm{msec}, \mathrm{SD}=32.64$; TMS at $400: 466 \mathrm{msec}, \mathrm{SD}=29.89$; TMS at 525: $457 \mathrm{msec}, \mathrm{SD}=39.31$ ) were almost identical to the mean $\mathrm{RT}$ revealed without TMS pulses ( $449 \mathrm{msec}, \mathrm{SD}=41.22$ ). This implies that applying no TMS and sham TMS at various time intervals after picture onset similarly does not result in behavioural changes in picture naming.

In contrast, real TMS over Broca's area did increase the RTs during picture naming compared to no TMS (454 msec, $\mathrm{SD}=43.89$ ). The RTs increased by approximately $15 \mathrm{msec}$ for the time windows at $150 \mathrm{msec}(470 \mathrm{msec}, \mathrm{SD}=45.88)$ and $225 \mathrm{msec}$ (471 $\mathrm{msec}, \mathrm{SD}=43.19)$. In contrast, the time window of 300 msec was characterised by a large effect of TMS on RTs of approximately $50 \mathrm{msec}(505 \mathrm{msec}, \mathrm{SD}=75.02)$ compared to no TMS. At 400 and $525 \mathrm{msec}$, however, RTs rapidly decreased again and went back to baseline (no TMS) level. This indicates

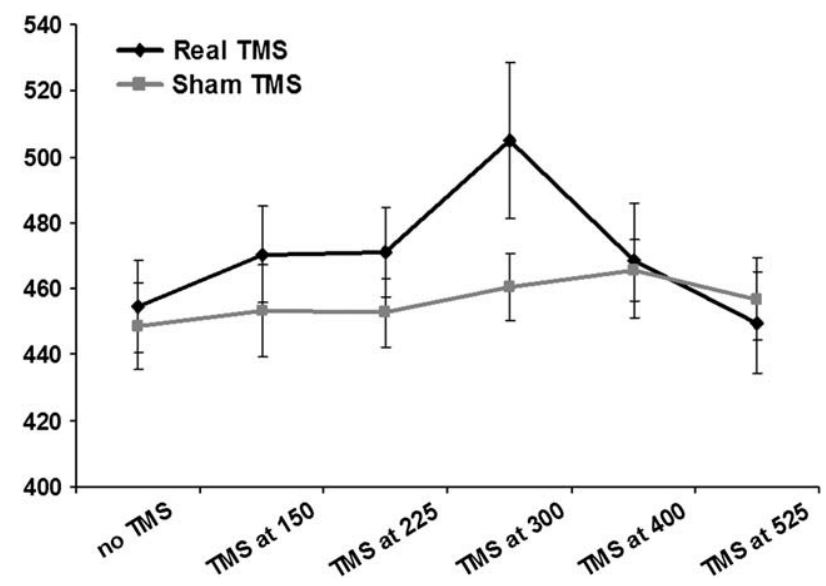

Fig. 3 - Behavioural results. Mean RTs (naming latencies) in msec (plus standard errors) for all time windows, separately shown for real (black line) versus sham (grey line) TMS. Only when applying real TMS at $300 \mathrm{msec}$ after picture presentation, a significant increase in RTs was found. 
that real TMS over Broca's area has a very time-specific effect on picture naming, only interfering with behaviour when applying tpTMS at $300 \mathrm{msec}$ after the onset of picture presentation. In Fig. 3, it can be seen that the RTs do not differ between real and sham TMS in the no TMS trials, whereas the RTs slowly diverge when a applying pulses at 150 and $225 \mathrm{msec}$, finding their peak difference in the time window of TMS at $300 \mathrm{msec}$, and finally go back to the same level again in the last two time windows, namely at TMS at $400 \mathrm{msec}$ and TMS at 525 msec.

In order to test whether the time- and stimulation typespecific changes in RTs also reached statistical significance, we entered the data into a two-factorial ANOVA. The twofactorial ANOVA with stimulation type (real TMS us sham TMS) and time window (no stimulation, stimulation at 150, $225,300,400$, and $525 \mathrm{msec}$ after stimulus presentation) as the two within-subject factors revealed a main effect of time window $[F(5,45)=3.63, p<.01]$, indicating that the effect of TMS over Broca's area differed between the various time points of stimulation. The analysis did not reveal a main effect of stimulation type $[F(1,9)=.98, p=.348]$. Importantly, the analysis yielded a significant interaction of stimulation type and time window $[F(5,45)=4.22, p<.01]$, demonstrating that the time-specific effect of TMS differed between real and sham TMS. To break down the interaction, simple contrasts were performed comparing the different time windows between the stimulation types. The correction for multiple comparisons was done following the Fisher's LSD procedure. These revealed a significant effect of stimulation type only in the time window of $300 \mathrm{msec}[F(1,9)=7.90, p<.05]$, while all other time windows showed no significant difference compared to baseline. Moreover, a significant interaction between stimulation type and time window was again only found in the time window of $300 \mathrm{msec}[F(1,9)=7.52, p<.05]$, while all time points before and after $300 \mathrm{msec}$ showed no significant difference between real and sham TMS.

This finding was further confirmed by separate one-factorial analyses of both real and sham TMS. Under sham stimulation, no difference between the time windows could be found $[F(5,45)=1.27, p=.293]$. Under real stimulation, however, a main effect of condition was revealed $[F(4$, $45)=5.55, p<.001]$. Simple contrasts were performed to compare the five conditions in which stimulation was applied at several time windows with the baseline condition in which no pulses were applied. This revealed a significant difference in RTs only for the condition in which stimulation took place at $300 \mathrm{msec}$ after stimulus presentation $[F(1,9)=9.04, p<.05]$.

\section{Discussion}

Making use of neuronavigated event-related TMS, we were able to define the exact time period at which Broca's area is critically engaged in the process of picture naming. Applying online tpTMS over Broca's area resulted in an increase in RTs in a picture naming task only when applied $300 \mathrm{msec}$ after picture presentation. In contrast, stimulating Broca's area at earlier time windows (150 $\mathrm{msec}$ and $225 \mathrm{msec}$ ) or at later time windows (400 $\mathrm{msec}$ and $525 \mathrm{msec}$ ) did not have a significant effect on RTs. Sham stimulation over Broca's area did not affect RTs at any time. Our data thus confirm the relevance of Broca's area during picture naming as suggested by previous studies (see Vigneau et al., 2006 for an overview), and provides new insights into the exact spatio-temporal characteristics of its specific contribution during speech production.

The question arises which of the different cognitive processes involved in speech production is disturbed at 300$350 \mathrm{msec}$ after picture presentation. Although our study did not aim at providing conclusive support in favour of a particular cognitive subprocess, it is still possible to discuss the spatiotemporal specificity of Broca's involvement during picture naming. This can be done with the help of predictions made by respective psycholinguistic models of speech production. Based on chronometric behavioural and electrophysiological data, an estimation of the entire time course of speech production has been made (Indefrey and Levelt, 2004). According to this estimation, the access of a lexical concept, followed by the retrieval of the lemmas takes approximately 225-275 msec (Schmitt et al., 2000; Thorpe et al., 1996; Glaser and Dungelhoff, 1984). Phonological encoding and syllabification then follows at approximately $350 \mathrm{msec}$ and takes around $100 \mathrm{msec}$ (depending on the length of the word (Schiller, 2006)). The final step before articulation, namely phonetic encoding lasts about $145 \mathrm{msec}$. Thus, the overall time required to name an object from a picture takes between 550 and $600 \mathrm{msec}$ on average (Levelt et al., 1998). However, since we only used monomorphemic, monosyllabic, and relatively familiar objects, and since naming these objects was well-trained, we obtained faster mean RTs of approximately $470 \mathrm{msec}$. Presumably, shorter RTs reflect an equidistant shortening of all the processes involved in speech production. On the basis of that assumption, tpTMS at 300 msec after picture onset is likely to disturb Broca's area in the process of syllabification. This interpretation is further supported by Indefrey and Levelt's (2004) study. They performed a meta-analysis of the relevant imaging literature on word production combined with an analysis of data on the time course of activation and reported specific regions and time windows of activation for the core processes of word production. They also proposed an involvement of Broca's area in the process of syllabification.

However, although our findings are compatible with psycholinguistic models of language production suggesting Broca's area to be involved in the process of syllabification, follow-up TMS studies are needed to support this interpretation. These studies could include respective control tasks that are computationally very similar to picture naming but do not comprise syllabification or introduce a parametric variation of word length and therefore vary the syllabication time. These studies might provide stronger empirical evidence that only the syllabification process (and no other cognitive process of picture naming) is being interfered with as a result of tpTMS over Broca's area at $300 \mathrm{msec}$ after picture onset.

In addition, it is important to note that the above interpretation is framed within the theoretical assumptions made in Levelt et al.'s (1999) discrete serial view of word production. There are, however, also other approaches to word production, including interactive activation theories (i.e., Dell, 1986). In Dell's theory, strictly speaking all levels of word encoding, e.g., the conceptual level, the lexical level, the morphological level and the phonological level, are activated simultaneously. 
Therefore, interactive activation theories would not predict a specific time window for the process of syllabification.

Finally, although it remains speculative which exact 'discrete' cognitive process of speech production is disturbed by TMS over Broca's area, our findings provide empirical insights into the temporal characteristics of the involvement of this brain area during overt picture naming. We show that the online tpTMS application over Broca's area during picture naming is capable of revealing that Broca's area is functionally relevant for successful speech production, and is capable of identifying the precise point in time at which the neural activity in Broca's area functionally contributes to the processes of overt picture naming.

\section{Acknowledgments}

T.S., N.O.S., and A.T.S. were supported by grants from the Netherlands Organisation for Scientific Research (NWO; grant number 452-06-003, 453-02-006, and 400-04-215). We thank our medical supervisor Cees van Leeuwen, and our independent physician Martin van Boxtel. Furthermore, we thank two anonymous reviewers for helpful comments on an earlier version of the manuscript.

\section{R E F E R E N C E S}

Andoh J, Artiges E, Pallier C, Riviere D, Mangin JF, Cachia A, et al. Modulation of language areas with functional MR imageguided magnetic stimulation. Neuroimage, 29: 619-627, 2006.

Baayen RH, Piepenbrock R, and Gulikers L. The CELEX Lexical Database (Release 2) [CD-ROM], Linguistic Data Consortium. Philadelphia, PA: University of Pennsylvania [Distributor], 1995.

Binder JR, Frost JA, Hammeke TA, Cox RW, Rao SM, and Prieto T. Human brain language areas identified by functional magnetic resonance imaging. Journal of Neuroscience, 17: 353-362, 1997.

Broca P. Remarques sur le siège de la faculté du langage articule, suivies d'une observation d'aphémie (Perte de la Parole). Bulletin de la Société Anatomique de Paris, 6: 330-357, 1861.

Brodmann K. Vergleichende Lokalisationslehre der Großhirnrinde in Ihren Prinzipien Dargestellt auf Grund des Zellenbaues. Leipzig: Johann Ambrosius Barth, 1909.

Cohen Kadosh R, Cohen Kadosh K, Schuhmann T, Kaas A, Goebel R, Henik A, et al. Virtual dyscalculia induced by parietal-lobe TMS impairs automatic magnitude processing. Current Biology, 17: 689-693, 2007.

Dell GS. A spreading-activation theory of retrieval in sentence production. Psychological Review, 93: 283-321, 1986.

Devlin JT, Matthews PM, and Rushworth MF. Semantic processing in the left inferior prefrontal cortex: a combined functional magnetic resonance imaging and transcranial magnetic stimulation study. Journal of Cognitive Neuroscience, 15: 71-84, 2003.

Gernsbacher MA and Kaschak MP. Neuroimaging studies of language production and comprehension. Annual Review of Psychology, 54: 91-114, 2003.

Glaser WR and Dungelhoff FJ. The time course of picture-word interference. Journal of Experimental Psychology Human Perception and Performance, 10: 640-654, 1984.

Indefrey $\mathrm{P}$ and Levelt WJ. The spatial and temporal signatures of word production components. Cognition, 92: 101-144, 2004.
Levelt WJ, Praamstra P, Meyer AS, Helenius P, and Salmelin R. An MEG study of picture naming. Journal of Cognitive Neuroscience, 10: 553-567, 1998.

Levelt WJ, Roelofs A, and Meyer AS. A theory of lexical access in speech production. The Behavioral and Brain Sciences, 22: 1-38. discussion 38-75, 1999.

Mottaghy FM, Hungs M, Brugmann M, Sparing R, Boroojerdi B, Foltys $\mathrm{H}$, et al. Facilitation of picture naming after repetitive transcranial magnetic stimulation. Neurology, 53: 1806-1812, 1999.

Mottaghy FM, Sparing R, and Topper R. Enhancing picture naming with transcranial magnetic stimulation. Behavioral Neurology, 17: 177-186, 2006.

Naeser MA, Martin PI, Nicholas M, Baker EH, Seekins H, Kobayashi M, et al. Improved picture naming in chronic aphasia after TMS to part of right Broca's area: an openprotocol study. Brain and Language, 93: 95-105, 2005.

Nixon P, Lazarova J, Hodinott-Hill I, Gough P, and Passingham R. The inferior frontal gyrus and phonological processing: an investigation using rTMS. Journal of Cognitive Neuroscience, 16: 289-300, 2004.

Pascual-Leone A, Walsh V, and Rothwell J. Transcranial magnetic stimulation in cognitive neuroscience-virtual lesion, chronometry, and functional connectivity. Current Opinion in Neurobiology, 10: 232-237, 2000.

Sack AT, Camprodon JA, Pascual-Leone A, and Goebel R. The dynamics of interhemispheric compensatory processes in mental imagery. Science, 308: 702-704, 2005.

Sack AT, Kohler A, Linden DE, Goebel R, and Muckli L. The temporal characteristics of motion processing in hMT/V5+: combining fMRI and neuronavigated TMS. Neuroimage, 29: 1326-1335, 2006.

Sack AT and Linden DE. Combining transcranial magnetic stimulation and functional imaging in cognitive brain research: possibilities and limitations. Brain Research Cognitive Brain Research, 43: 41-56, 2003.

Sakai KL, Noguchi Y, Takeuchi T, and Watanabe E. Selective priming of syntactic processing by event-related transcranial magnetic stimulation of Broca's area. Neuron, 35: 1177-1182, 2002.

Salmelin R. Clinical neurophysiology of language: the MEG approach. Clinical Neurophysiology, 118: 237-254, 2007.

Schiller NO. Lexical stress encoding in single word production estimated by event-related brain potentials. Brain Research, 1112: 201-212, 2006.

Schiller NO, Bles M, and Jansma BM. Tracking the time course of phonological encoding in speech production: an event-related brain potential study. Brain Research Cognitive Brain Research, 17: 819-831, 2003.

Schmitt BM, Munte TF, and Kutas M. Electrophysiological estimates of the time course of semantic and phonological encoding during implicit picture naming. Psychophysiology, 37: 473-484, 2000.

Shapiro KA, Pascual-Leone A, Mottaghy FM, Gangitano M, and Caramazza A. Grammatical distinctions in the left frontal cortex. Journal of Cognitive Neuroscience, 13: 713-720, 2001.

Thorpe S, Fize D, and Marlot C. Speed of processing in the human visual system. Nature, 381: 520-522, 1996.

Vigneau M, Beaucousin V, Herve PY, Duffau H, Crivello F, Houde $\mathrm{O}$, et al. Meta-analyzing left hemisphere language areas: phonology, semantics, and sentence processing. Neuroimage, 30: 1414-1432, 2006.

Walsh V and Pascual-Leone A. Neurochronometrics of Mind: Transcranial Magnetic Stimulation in Cognitive Science. Cambridge, MA: MIT Press, 2003.

Wernicke C. Der Aphasische Symptomencomplex, Eine Physiologische Studie auf Anatomischer Basis. Breslau: Cohn \& Weigert, 1874. 